\section{Neutralizing human monoclonal antibodies prevent Zika virus infection in macaques}

\author{
Diogo M. Magnani, ${ }^{1 *}$ Thomas F. Rogers, ${ }^{2 *}$ Nathan Beutler, ${ }^{2}$ Michael J. Ricciardi, ${ }^{1}$ Varian K. Bailey, \\ Lucas Gonzalez-Nieto, ${ }^{1}$ Bryan Briney, ${ }^{2}$ Devin Sok, ${ }^{2}$ Khoa Le, ${ }^{2}$ Alexander Strubel, ${ }^{2}$ \\ Martin J. Gutman, ${ }^{1}$ Núria Pedreño-Lopez, ${ }^{1}$ Nathan D. Grubaugh, ${ }^{2}$ Cassia G. T. Silveira, ${ }^{3}$ \\ Helen S. Maxwell, ${ }^{1}$ Aline Domingues, ${ }^{1}$ Mauricio A. Martins, ${ }^{1}$ David E. Lee, ${ }^{4}$ Erica E. Okwuazi, ${ }^{4}$ \\ Sherrie Jean, ${ }^{4}$ Elizabeth A. Strobert, ${ }^{4}$ Ann Chahroudi, ${ }^{4,5}$ Guido Silvestri, ${ }^{4}$ Thomas H. Vanderford, ${ }^{4}$ \\ Esper G. Kallas, ${ }^{3}$ Ronald C. Desrosiers, ${ }^{1}$ Myrna C. Bonaldo, ${ }^{6}$ Stephen S. Whitehead, ${ }^{7}$ \\ Dennis R. Burton, ${ }^{2,8+}$ David I. Watkins ${ }^{1 \dagger}$
}

Therapies to prevent maternal Zika virus (ZIKV) infection and its subsequent fetal developmental complications are urgently required. We isolated three potent ZIKV-neutralizing monoclonal antibodies (nmAbs) from the plasmablasts of a ZIKV-infected patient-SMZAB1, SMZAb2, and SMZAb5-directed against two different domains of the virus. We engineered these nmAbs with Fc LALA mutations that abrogate $\mathrm{Fc} \gamma$ receptor binding, thus eliminating potential therapy-mediated antibody-dependent enhancement. We administered a cocktail of these three nmAbs to nonhuman primates 1 day before challenge with ZIKV and demonstrated that the $\mathrm{nmAbs}$ completely prevented viremia in serum after challenge. Given that numerous antibodies have exceptional safety profiles in humans, the cocktail described here could be rapidly developed to protect uninfected pregnant women and their fetuses.

\section{INTRODUCTION}

Zika virus (ZIKV) infection is a serious global public health threat with the potential to affect millions of individuals (1-4). Several locations will remain susceptible to yearly ZIKV outbreaks, and new regions of the world will likely experience epidemics similar to the one described in South America in 2016. Developing novel preventive therapies will be central to limiting complications associated with the future epidemics. Of particular concern is the link between ZIKV infection of pregnant women and abnormal fetal development (1-3). Prophylaxis using antibodies constitutes a well-established class of clinical intervention, including preventative and therapeutic uses in expectant mothers and premature infants $(5,6)$. The administration of human neutralizing monoclonal antibodies (nmAbs) in pregnant women to prevent ZIKV infection could be especially beneficial because they are generally considered safe and maternal antibodies cross the placenta and are the predominant means of fetal immunity (7). Thus, a passively administered appropriately engineered human nmAb may be able to protect a fetus from ZIKV infection. nmAb therapy is therefore likely to be one of the most promising interventions to prevent and treat ZIKV infection during pregnancy.

\section{RESULTS}

To isolate candidate potent $\mathrm{nmAb}$ for use in passive transfer therapies, we cloned antibody genes from blood-derived plasmablasts of a ZIKV1Department of Pathology, University of Miami Leonard M. Miller School of Medicine,
Miami, FL 33136, USA. ${ }^{2}$ Department of Immunology and Microbiology and International
AIDS Vaccine Initiative Neutralizing Antibody Center, The Scripps Research Institute, La
Jolla, CA 92037, USA. ${ }^{3}$ Division of Clinical Immunology and Allergy, School of Medicine,
University of São Paulo, São Paulo, São Paulo, Brazil. ${ }^{4}$ Yerkes National Primate Research
Center, Emory University, Atlanta, GA 30329, USA. ${ }^{5}$ Department of Pediatrics, Emory
University, Atlanta, GA 30322, USA. ${ }^{6}$ Laboratório de Biologia Molecular de Flavivírus, In-
stituto Oswaldo Cruz, Fiocruz, Rio de Janeiro 21040-360, Brazil. ' ${ }^{7}$ Laboratory of Infectious
Diseases, National Institute of Allergy and Infectious Diseases, National Institutes of
Health, Bethesda, MD 20892, USA. ${ }^{8}$ Ragon Institute of MGH, MIT and Harvard, Cambridge,
MA 02139, USA.
*These authors contributed equally to this work.
tCorresponding author. Email: burton@scripps.edu (D.R.B.); dwatkins@med.miami. edu (D.I.W.) infected subject from Colombia in the acute phase. After individual amplification of the heavy $(\mathrm{H})$ and light $(\mathrm{L})$ chains from the isolated $B$ cells, we expressed and purified $91 \mathrm{mAbs}$. These $\mathrm{mAbs}$ were tested for neutralization, and 11 of them reduced ZIKV infection by greater than $80 \%$ at $1 \mu \mathrm{g} \mathrm{ml}^{-1}$ (fig. S1). Because our long-term goal is to prevent infection (or reduce viral replication) with nmAbs in humans in resource-limited areas, we selected the three most potent nmAbs: SMZAb1 (IGHV3-23*04 and IGKV1-5*03), SMZAb2 (IGHV1-69*01 and IGLV8-61*01), and SMZAb5 (IGHV3-23*01 and IGKV1-5*03). The isolated nmAbs had, on average, $18 \%$ heavy chain nucleotide mutations, with antibodies SMZAb1 and SMZAb5 both representing related variants of the IGHV3-23 gene family. The three nmAbs have half-maximal neutralization $\left(\mathrm{Neut}_{50}\right.$ ) potencies of less than $500 \mathrm{ng} \mathrm{ml}^{-1}$ (Fig. 1 and tables S1 to S3) and were selected for in vivo studies so that antiviral effects would be achieved at low concentrations in vivo and $\mathrm{nmAb}$ costs would be minimized.

The ZIKV E protein is the main target of nmAbs and contains three domains, with most of the anti-ZIKV nmAb targeting either domain III or the fusion loop epitope in domain II (8). We screened our three most potent nmAbs for their ability to recognize different regions of the ZIKV E protein in domain binding experiments (fig. S2). We used a domain III protein binding enzyme-linked immunosorbent assay (ELISA) to identify nmAbs that target this domain. We also used a $\mathrm{mAb}$ competition assay to evaluate mAbs, which target epitopes that overlap with the fusion loop epitope targeted by the wellcharacterized anti-flavivirus mAb, 4G2 (clone D1-4G2-4-15 MAB10216, MilliporeSigma). On the basis of these analyses, we demonstrated that our three most potent nmAbs bind to two different regions of the virus; SMZAb1 and SMZAb5 bind domain III, and SMZAb2 binds domain II.

Flaviviruses are RNA viruses and have been shown to readily escape $n m A b$ therapy $(9,10)$. To avoid this possible outcome, we screened our three nmAbs for their ability to select for escape mutants in vitro using previously published protocols (11).

Because our nmAbs showed some cross-reactivity with dengue virus (DENV) (figs. S3 and S4), we engineered them to prevent any 
potential antibody-dependent enhancement (ADE) effects in future applications by incorporating the L234A and L235A (LALA) immunoglobulin $\mathrm{G}(\mathrm{IgG} 1)$ mutations, which reduce or prevent $\mathrm{Fc}-\gamma$ receptor (Fc $\gamma \mathrm{R})$ binding (12). We then produced large quantities of the nmAbs

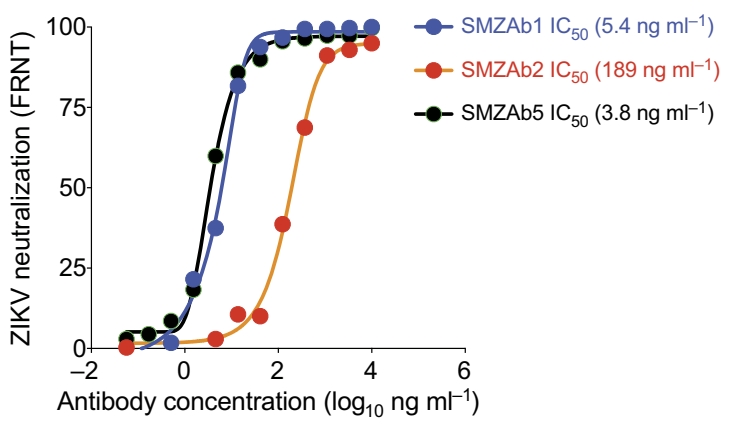

Fig. 1. The plasmablast-derived human nmAbs SMZAb1, SMZAb2, and SMZAb5 neutralize ZIKV in vitro. Ninety-one mAbs generated from a ZIKV-infected patient were screened for ZIKV neutralization potency using Vero cell infectivity assays, and the three most potent-SMZAb1, SMZAb2, and SMZAb5-neutralized ZIKV at low concentrations. The neutralization titers were determined by focus reduction neutralization test (FRNT). by transfection of mammalian cells and subsequent purification. We retested our three LALA-modified nmAbs before infusion in two different neutralization assays and determined that they all neutralized ZIKV with Neut $_{50}$ and $50 \%$ plaque reduction neutralization test $\left(\mathrm{PRNT}_{50}\right)$ values in the nanogram per milliliter range (tables $\mathrm{S} 1$ and S3).

We next tested the ability of the nmAbs to protect against ZIKV infection in eight Indian rhesus macaques (Macaca mulatta) (table S4). We recently developed a nonhuman primate (NHP) ZIKV macaque challenge model using a low-passage primary isolate (Rio U-1 2016), recovered from the urine of a pregnant woman during the 2016 outbreak in Rio de Janeiro (13). In our first experimental group (group 1; Fig. 2A) of four macaques, we delivered a cocktail of SMZAb1, SMZAb2, and SMZAb5 at $20 \mathrm{mg} \mathrm{kg}^{-1}$ (of each nmAb) to achieve plasma levels exceeding $1000 \times$ the Neut ${ }_{50}$ of each $n m A b$. We also delivered the same dose of a human IgG1 isotype control (wild-type), CB1 (cannabinoid receptor type 1), to four control macaques (group 2; Fig. 2A). We then challenged the macaques subcutaneously with 1000 plaque-forming units (PFU) of our low-passage primary isolate ZIKV stock 1 day after passive transfer. Because the actual amount of ZIKV delivered to humans during mosquito feeding is unknown (14), we chose an infectious dose similar to that which has been recently used in ZIKV
A

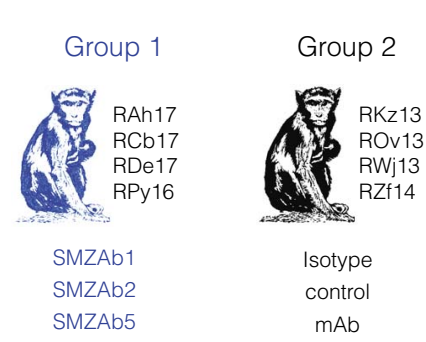

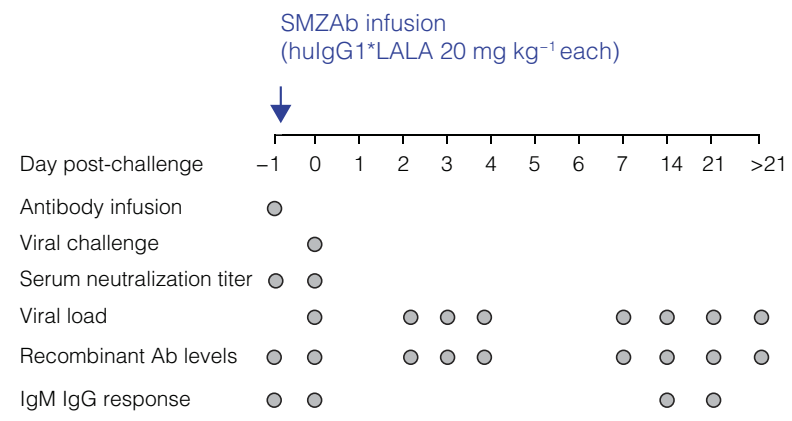

B

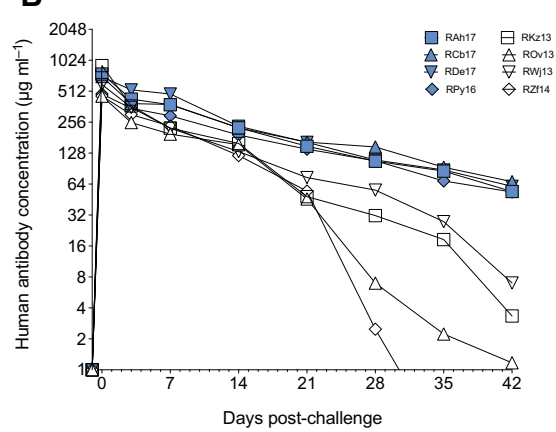

D

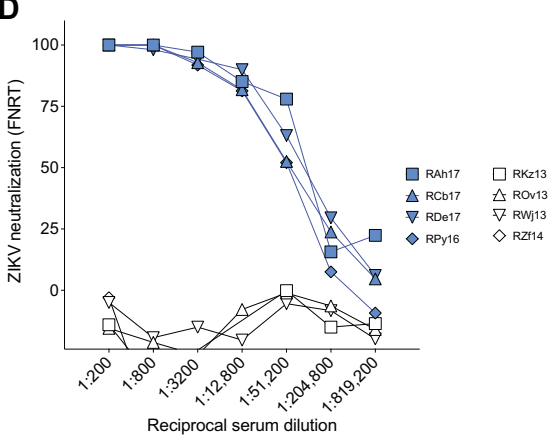

C

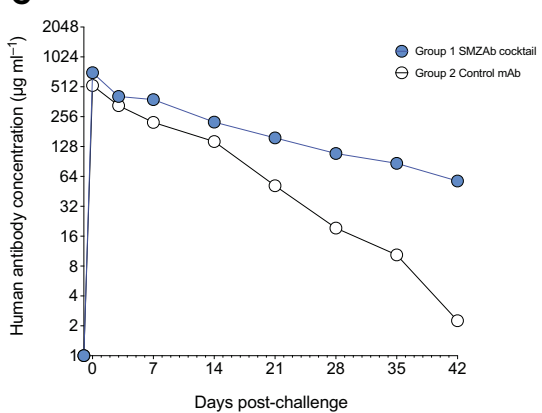

E

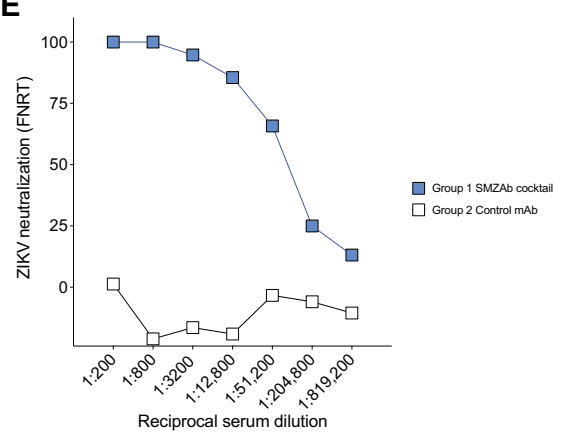

Fig. 2. Study design and pharmacokinetics of SMZAb cocktail administration to Indian rhesus macaques. (A) A cocktail containing the three nmAbs-SMZAb1, SMZAb2, and SMZAb5-at a dose of $20 \mathrm{mg} \mathrm{kg}^{-1}$ each were administered to four rhesus macaques (group 1). A control group (group 2) received the human CB1 isotype control at a dose of $60 \mathrm{mg} \mathrm{kg}^{-1}$ total. All animals were challenged with 1000 PFU of ZIKV Rio U-1 20161 day after mAb administration. Serum was collected at the indicated time points for viral load, neutralization, lgG, and IgM measurements. (B) Serum levels of recombinant antibodies were determined by ELISA. Antibody level values for each SMZAb cocktail (blue) or control mAb (open symbols) animal. (C) Median values for group 1 (blue) and group 2 (open symbols). (D) ZIKV-neutralizing activity in serum after mAb infusion was determined by FRNT. Median ZIKV foci neutralization percentage values for each SMZAb cocktail (blue) or control mAb (open symbols) animal. (E) Median values for group 1 (blue) and group 2 (open symbols). 
A

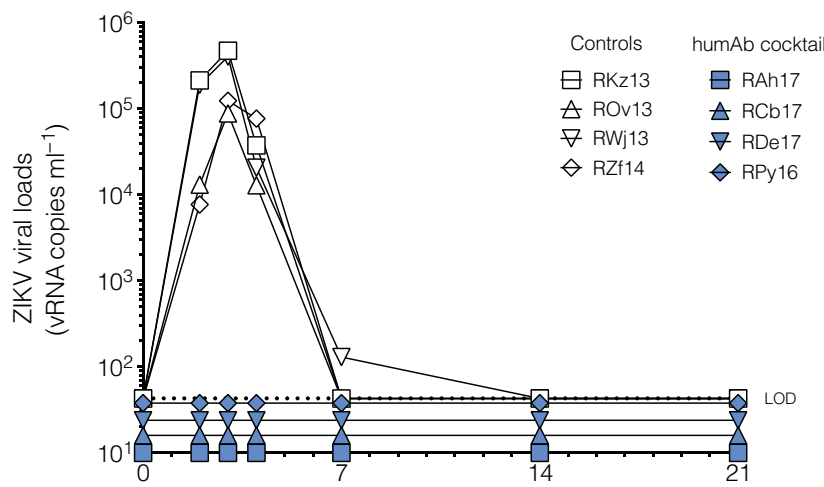

Days post-challenge
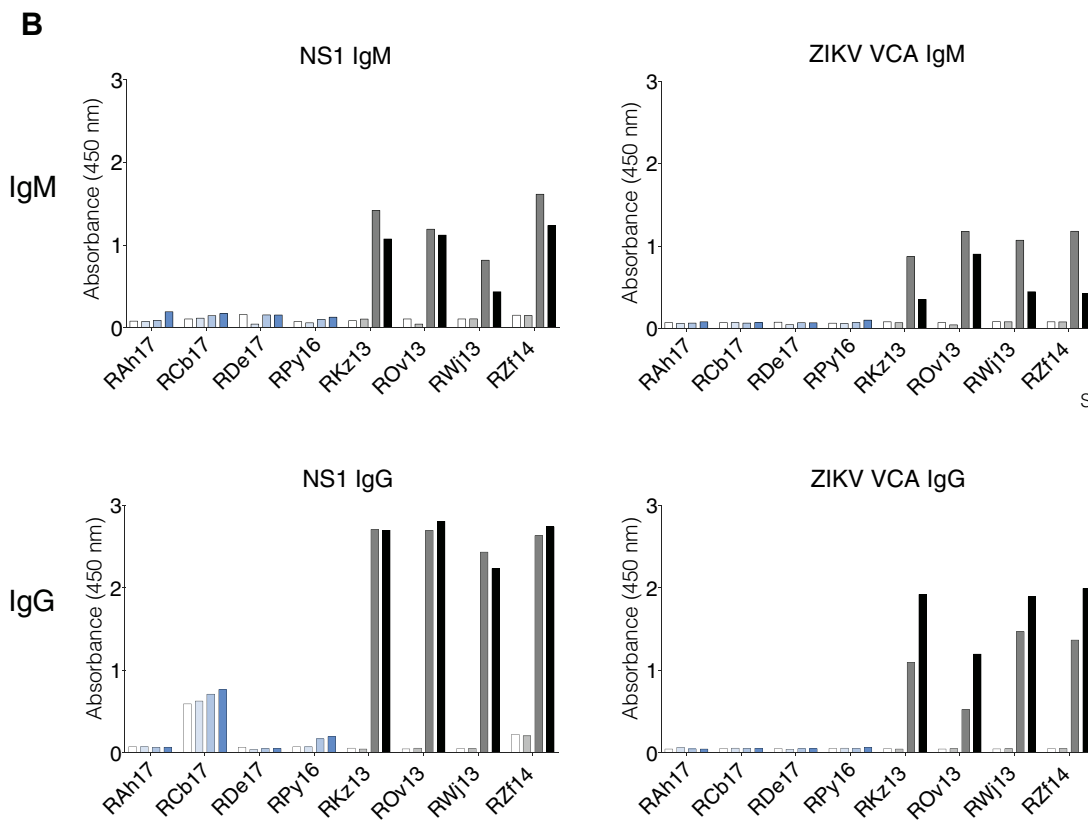

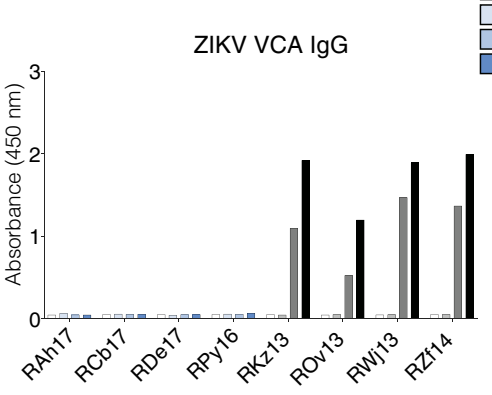

Animal ID

Fig. 3. Viral loads and humoral responses after ZIKV challenge. (A) A cocktail containing the three nmAbs-SMZAb1, SMZAb2, and SMZAb5 - at a dose of $20 \mathrm{mg} \mathrm{kg}^{-1}$ each were administered to four rhesus macaques (group 1). A control group (group 2) received the human CB1 isotype control at a dose of $60 \mathrm{mg} \mathrm{kg}^{-1}$ total. All animals were challenged with 1000 PFU of ZIKV Rio U-1 20161 day after mAb administration. Serum viral loads for SMZAb-treated macaques (blue) and control CB1 mAb-treated macaques (open symbols). Dotted lines indicate the limit of detection (LOD) of the assay. humAb, human antibody. (B) Humoral lgM and lgG responses of challenged animals against whole ZIKV or NS1. Serum binding (diluted 1:100) was measured by ELISA using rhesus-specific antibodies.

vaccination and challenge experiments in NHPs $(15,16)$. After infusion, we monitored $\mathrm{mAb}$ levels using an antibody ELISA. Levels of our nmAbs averaged about $600 \mu \mathrm{g} \mathrm{ml}^{-1}$ at day of challenge and about $500 \mu \mathrm{g} \mathrm{ml}^{-1}$ at day 7 after challenge, well above $1000 \times$ the Neut $_{50}$ of these potent nmAbs (Fig. 2, B and C). We also monitored serum neutralizing activity on the day of challenge and demonstrated that sera from the macaques infused with our ZIKV-specific nmAbs neutralized ZIKV at a dilution of about 1:50,000 (Fig. 2, D and $\mathrm{E}$, and fig. S5).

Our $\mathrm{nmAb}$ cocktail appeared to confer sterilizing immunity on the four treated macaques. To determine whether our nmAbs had blocked ZIKV infection in the group 1 animals, we measured serum viral concentrations by quantitative real-time reverse transcription polymerase chain reaction (qRT-PCR) and plaque assay from day 0 to day 21 after challenge. Our ZIKV-specific nmAb cocktail completely prevented viral replication in all four $\mathrm{nmAb}$-treated macaques in group 1 (Fig. $3 \mathrm{~A}$ and table S5). Because occult viral replication can occur in the absence of plasma viremia, we then tested macaque IgG and IgM responses against ZIKV in the treated and control animals. We could find no evidence for any ZIKV-specific antibody responses against either NS1 or whole virus in the nmAb-treated macaques (Fig. 3B). As expected, the control macaques mounted robust ZIKV-specific IgG and IgM responses (Fig. 3B).

\section{DISCUSSION}

$\mathrm{ADE}$ is a serious technical hurdle to the development of vaccines against flaviviruses like ZIKV (17). Specially engineered nmAbs would avoid this unfortunate consequence of vaccination. ADE has been well described in the setting of DENV $(18,19)$, where subneutralizing concentrations of neutralizing antibodies via an Fc $\gamma$ R-mediated mechanism (20) bind viral particles and direct them to cells of the myeloid lineage. ADE can transform a secondary DENV infection into potentially fatal hemorrhagic fever (21), and antiDENV or anti-WNV (West Nile virus) sera can enhance ZIKV infection in vivo (22). It has already been established that immune responses against ZIKV and DENV crossreact $(8,23,24)$, raising the possibility that a vaccine for one of these viruses could result in a poor outcome after infection with another. It is also of concern that individuals with a diminished immune response against a ZIKV vaccine run the risk of a much more severe ZIKV (or DENV) infection. For this reason, and others, it will take a number of years of testing before a ZIKV vaccine can safely be administered to women of childbearing age. Additionally, millions of individuals in an at-risk area would have to volunteer to be vaccinated to provide sufficient herd immunity to limit ZIKV-caused birth defects. Recombinant nmAbs can be engineered through well-established procedures to both avoid ADE and increase their half-lives by more than threefold, resulting in efficacious levels of mAbs for more than 6 months after a single injection of $\mathrm{mAb}(25)$. Thus, the quickest and most effective way to prevent fetal defects caused by ZIKV may be to develop human nmAbs or cocktails of these nmAbs that can be administered to pregnant women. Although other antibodies have shown some degree of efficacy in preventing or limiting mouse ZIKV infections (26), they remain to be evaluated in 
NHP models that can recapitulate essential aspects of human ZIKV pathology. The coformulation of three antibodies that include epitope specificity for both domains II and III was selected to reduce the probability of ZIKV E protein escape variants. In this NHP study, we observed no evidence of viral replication in vivo and therefore are hopeful that the delivery of these three antibodies in humans as a ZIKV preventative therapy would prevent the generation of viral escape as well. It should be noted, however, that our nmAb cocktail was not tested in pregnant NHPs. Thus, the nmAb cocktail described here warrants additional preclinical testing in pregnant macaques as a strategy to prevent fetal defects caused by ZIKV infection.

\section{MATERIALS AND METHODS Study design}

We have tested the hypothesis that a cocktail of three ZIKV-neutralizing antibodies is sufficient for preventing ZIKV infection in rhesus macaques. A control group and a test group of four macaques each were used in this efficacy experiment. Macaques were selected on the basis of availability and were not randomized during assignment. Because the supply of mAbs was limited, we selected the lighter macaques to receive the SMZAbs. The primary outcome measured was the presence of viral RNA (vRNA) in serum, performed in two independent assays. Primary data are given in tables S5 and S6.

\section{Human research}

Preexisting blood samples were obtained through Antibody Systems Inc. under The Scripps Research Institute IRB-15-6683. Research on human subjects was conducted in compliance with existing regulations relating to the protection of human subjects. All human subjects were consented, and all specimens, data, and human subject research were gathered by Antibody Systems Inc.

\section{Animal experiments}

The eight Indian rhesus macaques (M. mulatta) used in this study were housed at the Yerkes National Primate Research Center (YNPRC). The YNPRC is fully accredited by Association for the Assessment and Accreditation of Laboratory Animal Care International, Animal Welfare Assurance No. A3180-01. Animals were cared for in accordance with the National Research Council Guide for the Care and Use of Laboratory Animals, and the Animal Welfare Act Animal experiments were approved by the Institutional Animal Care and Use Committee of Emory University (protocol YER-2003415). The macaques were separated in two groups as follows: group 1 (SMZAb cocktail, $n=4)$ and group 2 (isotype control $\mathrm{mAb}, n=4$ ). The mAb cocktail was prepared in saline bags and administered intravenously into each animal. All animals were challenged 1 day after mAb administration with $1 \times$ $10^{3}$ PFU of ZIKV Rio U-1 2016 delivered subcutaneously. After the challenge, we collected serum at the indicated time points to measure viremia, mAb levels, and seroconversion.

\section{Viruses}

ZIKV strain Rio U-1 2016 was isolated in Rio de Janeiro, Brazil, in 2016 (KU926309). Viral challenge stocks were prepared by propagating the virus in Vero cells for two passages after virus isolation (13). Virus concentrations in the stocks were quantitated by viral plaque assay. The viral stocks were diluted in Leibovitz's L-15 and SPG media as described previously (27). DENV1 (West Pac74; U88535.1), DENV2 (New Guinea C; AF038403.1), DENV3 (Sleman/78; AY648961), DENV4
(Dominica/8129; AF326573.1), ZIKV (MR766; AY632535.2), and ZIKV (Paraiba/2015; KX280026) were propagated in Vero cells (American Type Culture Collection) and used for binding virus capture assays (VCAs) and neutralization assays as described below.

\section{mAb isolation and screening}

Peripheral blood mononuclear cells were isolated as previously described (28). Plasmablasts were sorted into 96-well plates by flow cytometry by sorting for $\mathrm{CD} 3^{-} \mathrm{CD} 19^{+} \mathrm{CD} 20^{\text {low }} \mathrm{CD} 38^{\text {hi }} \mathrm{CD} 27^{\text {hi }}$ cells. The sorts were at a density of one cell per well for antibody chain pairing. Reverse transcription and PCR amplification of heavy and light chain variable genes were performed, and the antibodies were assembled for each source cell.

\section{Focus reduction neutralization test}

Virus-specific neutralizing antibody responses were titrated essentially as previously described (29). Briefly, plasma or antibody was serially diluted in minimal essential medium (MEM) (Corning Cellgro) containing 5\% heat-inactivated fetal bovine serum (FBS) (Gibco-Invitrogen) and incubated for 1 hour at $37^{\circ} \mathrm{C}$ with virus. After incubation, the antibody-virus or plasma-virus mixture was added in triplicate to 96-well plates containing $80 \%$ confluent monolayers of Vero E6 cells. Plates were incubated for 1.5 hours at $37^{\circ} \mathrm{C}$. After incubation, wells were overlaid with $1 \%$ methylcellulose in supplemented MEM with 2\% heat-inactivated FBS (Gibco-Invitrogen) and 1:100 Hepes. Plates were incubated at $37^{\circ} \mathrm{C}, 5 \% \mathrm{CO}_{2}$ for 40 hours, after which cells were fixed and permeabilized with Perm/Wash buffer (BD Biosciences) for $5 \mathrm{~min}$. After permeabilization, cells were incubated with 1:2000 dilution of anti-flavivirus antibody (MAB10216, EMD Millipore) for 2 hours and then washed with phosphate-buffered saline (PBS). After washing, cells were incubated with anti-mouse horseradish peroxidase (HRP)-conjugated secondary antibody (115035146, Jackson ImmunoResearch Laboratories) in Perm/Wash buffer for 2 hours. After washing of cells with PBS, plates were developed with peroxidase substrate (KPL). The endpoint titer was determined to be the highest dilution with a $50 \%$ reduction $\left(\mathrm{IC}_{50}\right)$ in the number of plaques compared to control wells.

\section{Plaque reduction neutralization test}

PRNTs were conducted as previously described (27). Briefly, serum samples were serially diluted in 199 media supplemented with $2 \%$ human serum albumin, 5\% FBS, and gentamicin. ZIKV was diluted to a final concentration of $\sim 500$ to $1000 \mathrm{PFU} \mathrm{ml}^{-1}$ in the same diluent and added to equal volumes of the diluted sample. The virus-serum mixture was incubated at $37^{\circ} \mathrm{C}$ for $60 \mathrm{~min}$. Cell culture medium was removed from $90 \%$ confluent monolayer cultures of Vero cells on 24-well plates, and $100 \mu \mathrm{l}$ of the virus per mAb mixture was transferred onto duplicate cell monolayers. Cell monolayers were incubated for $60 \mathrm{~min}$ at $37^{\circ} \mathrm{C}$ and overlaid with $1 \%$ methylcellulose in Opti-MEM (Thermo Fisher Scientific) supplemented with 2\% FBS, $2 \mathrm{mM}$ glutamine, and gentamicin $\left(50 \mu \mathrm{g} \mathrm{ml}^{-1}\right)$. Samples were incubated at $37^{\circ} \mathrm{C}$ for 4 days, after which plaques were visualized by immunoperoxidase staining and $\mathrm{PRNT}_{50}$ was calculated.

\section{Flow cytometry-based neutralization assay}

The neutralizing potency of the mAbs was measured using a flow cytometry-based assay $(30,31)$. Briefly, recombinant mAbs were diluted and preincubated with ZIKV (Paraiba 2015, KX280026.1) in a final volume of $220 \mu \mathrm{l}$ for 1 hour at $37^{\circ} \mathrm{C}$. The virus and $\mathrm{mAb}$ mixture 
$(100 \mu \mathrm{l})$ was added onto wells of a 24 -well plate of $100 \%$ confluent Vero cell monolayers in duplicate. The inoculum was incubated in a $37^{\circ} \mathrm{C}$ incubator at $5 \% \mathrm{CO}_{2}$ for 1 hour with agitation of the plates every $15 \mathrm{~min}$. After 1 hour, the virus and mAb-containing supernatants were aspirated and the wells were washed with media. Fresh media were then added, and the plates were incubated for a total of 24 hours. Cells were trypsinized with $0.5 \%$ trypsin (Life Technologies), fixed (BD Cytofix), and permeabilized (BD Cytoperm). Viral infection was detected with the $4 \mathrm{G} 2$ antibody recognizing ZIKV or DENV, followed by staining with an anti-mouse IgG2a-allophycocyanin fluorophore-conjugated secondary reagent (BioLegend). Neut 50 was calculated using a nonlinear regression analysis with Prism 7.0 software (GraphPad Software). The ZIKV Paraiba 2015 strain was used in our neutralization assays.

\section{Virus capture assay}

Antibody binding to whole virus was determined in a side-by-side DENV1, DENV2, DENV3, DENV4, and ZIKV VCA ELISA. The ELISA plate was coated with the mouse anti-flavivirus mAb $4 \mathrm{G} 2$ diluted 1:1000 in carbonate binding buffer and incubated overnight at $4^{\circ} \mathrm{C}$. The next day, the plate was washed five times with PBSTween 20, and the wells were blocked with 5\% nonfat dry milk in PBS for 1 hour at $37^{\circ} \mathrm{C}$. After the block, the plate was washed and each virus was added to the corresponding VCA wells and incubated for 1 hour at room temperature. Subsequently, the plate was washed with PBS, and mAbs from different time points diluted in 5\% nonfat dry milk with PBS were added to designated wells and incubated for 1 hour at $37^{\circ} \mathrm{C}$. After sample addition, plates were washed and detection was carried out using one of the following antibodies: goat antihuman IgG-HRP (1:10,000 dilution; 2045-05, SouthernBiotech), mouse anti-monkey IgG-HRP (1:4000 dilution; 4700-05, SouthernBiotech), or goat anti-human IgM-HRP (1:2000 dilution; 2023-05, SouthernBiotech). The diluted detection antibody was added to all wells and incubated for 1 hour at $37^{\circ} \mathrm{C}$. The plate was then washed, and the wells were developed with the tetramethylbenzidine (TMB) substrate at room temperature for 3 to $4 \mathrm{~min}$. The reaction was then stopped with the TMB solution, and absorbance was read at $450 \mathrm{~nm}$.

\section{NS1 ELISA}

ZIKV-NS1-specific antibodies in serum were detected by ELISA. To begin, the plate was coated with ZIKV-NS1 antigen (MBS568704, MyBioSource) diluted to $10 \mu \mathrm{g} \mathrm{ml}^{-1}$ in carbonate binding buffer and incubated overnight at $4^{\circ} \mathrm{C}$. The following day, the plate was washed five times with PBS-Tween 20 and all wells were blocked with $5 \%$ nonfat dry milk in PBS for 1 hour at $37^{\circ} \mathrm{C}$. After the block, the plate was washed, and serum samples diluted 1:100 were added to corresponding wells and incubated for 1 hour at $37^{\circ} \mathrm{C}$. Subsequently, the plate was washed five times, and IgG or IgM detection was carried out. ZIKVNS1-specific rhesus IgG and IgM were detected using the mouse antimonkey IgG-HRP (1:4000 dilution; 4700-05, Southern Biotech) and the goat anti-human IgM-HRP (1:2000 dilution; 2023-05, Southern Biotech), respectively. The diluted detection antibodies were added to corresponding wells and incubated for 1 hour at $37^{\circ} \mathrm{C}$. The plate was then washed eight times and developed with TMB substrate at room temperature for 2 to $3 \mathrm{~min}$. The reaction was then stopped with TMB stop solution, and the absorbance was read at $450 \mathrm{~nm}$.

\section{In vivo human antibody quantitation by ELISA}

The presence of the recombinant nmAbs in sera was quantitated with an ELISA specific for human antibodies. Briefly, 96-well ELISA plates were coated overnight with the monkey antibody-adsorbed goat antihuman IgG (5 $\mathrm{g} \mathrm{m} \mathrm{ml}^{-1} ; 2049-01$, Southern Biotech) diluted in PBS. Each plate was washed with PBS-Tween 20, and the wells were blocked with $5 \%$ nonfat dry milk in PBS for 1 hour at $37^{\circ} \mathrm{C}$. Subsequently, the plate was washed with PBS and serum samples were added to designated wells. After 1 hour of incubation at $37^{\circ} \mathrm{C}$, the plate was washed and detection was carried out using an HRP-conjugated goat anti-human IgG (2045-05, Southern Biotech), which was added to all wells at a dilution of 1:10,000. After 1 hour of incubation at $37^{\circ} \mathrm{C}$, the plate was washed with PBS-Tween 20 and developed with TMB substrate (Millipore) at room temperature for 3 to $4 \mathrm{~min}$. Reaction was then stopped with TMB stop solution, and absorbance was read at $450 \mathrm{~nm}$.

\section{Measurement of vRNA load (qRT-PCR)}

The assay for the quantification of viral loads in sera was based on a previously validated qRT-PCR assay $(32,33)$. Briefly, RNA was extracted from $280 \mu \mathrm{l}$ of frozen sera using the QIAamp Viral RNA Mini Kit (Qiagen). The total nucleic acid was eluted in two centrifugation steps with $40 \mu$ of Buffer AVE each. A qRT-PCR was then carried out with $20 \mu \mathrm{l}$ of samples and $10 \mu \mathrm{l}$ of primer, probes, and TaqMan Fast Virus 1-Step Master Mix (Applied Biosystems). We used precombined probe and primers (500 nM primers and $250 \mathrm{nM}$ probe; IDT Technologies). The primer and probe sequences were designed to match sequences to the ZIKV isolate (KU926309) and were as follows: primer 1, 5' '-TTGAAGAGGCTGCCAGC-3'; primer 2, 5' -CCCACTGAACCCCATCTATTG-3'; and probe, 5'-TGAGACCCAGTGATGGCTTGATTGC-3'. The probe was double-quenched (ZEN/ Iowa Black FQ) and labeled with the FAM dye (IDT Technologies). Tenfold serial dilutions of in vitro transcript RNA starting at about $5 \times$ $10^{5}$ copies $\mu \mathrm{l}^{-1}$ were used as standards, and results were reported as the equivalent vRNA genomes per milliliter.

\section{Measurement of viral load (plaque)}

Quantification of ZIKV PFU in serum was determined as described before for PRNT, without the antibody incubation step.

\section{Domain III binding ELISA}

The domain specificity of our recombinant nmAbs was determined using Zika domain III recombinant protein ELISA. Ninety-six-well high-binding plates were coated overnight with Zika domain III recombinant protein $\left(5 \mu \mathrm{g} \mathrm{ml}^{-1}\right)$, supplied by D. Fremont and previously described (34), diluted in PBS. Each plate was washed three times with PBS-Tween 20, and the wells were blocked with $3 \%$ bovine serum albumin (BSA) in water for 1.5 hours at room temperature. Subsequently, the plate was washed three times with PBS-Tween 20, and our recombinant nmAbs were added to their designated wells at starting concentrations of $50 \mu \mathrm{g} \mathrm{ml}^{-1}$ with subsequent sixfold dilutions. After 1.5 hours of incubation at room temperature, the plate was washed and detection was carried out using anti-human IgG-AP (109055098, Jackson ImmunoResearch Laboratories), which was added to all wells at a dilution of 1:2000. After 1 hour of incubation at room temperature, the plate was washed and developed with phosphatase substrate (MilliporeSigma) at room temperature. The plates were immediately read at $405 \mathrm{~nm}$, with 5-min incubations at room temperature between reads.

\section{G2 mAb competition ELISA}

To further determine the domain specificity of our recombinant nmAbs, a competition ELISA was performed. Plates were coated overnight with 
ZIKV Envelope protein $\left(2 \mu \mathrm{g} \mathrm{ml}^{-1}\right)$ (ZIKV-SU-ENV100, Native Antigen) diluted in PBS. Each plate was washed three times with PBS-Tween 20 , and the wells were blocked with $3 \%$ BSA in water for 1.5 hours at room temperature. Subsequently, the plate was washed three times with PBS-Tween 20, and antibodies, 4G2 and a known domain III binding $\mathrm{mAb}$ characterized in our laboratory, ADI24255, were added to their designated wells at concentrations of $25 \mathrm{\mu g} \mathrm{ml}^{-1}$ with subsequent 10 -fold dilutions (35). After 1.5 hours of incubation at room temperature, the plate was washed and our previously biotinylated nmAbs (EZ-LINK NHS-Biotin, Thermo Fisher Scientific) were added to their designated wells. After 1.5 hours of incubation at room temperature, the plate was washed and alkaline phosphatase-conjugated streptavidin (016059-084, Jackson ImmunoResearch Laboratories) was added to all wells at a dilution of 1:2000. After 1 hour of incubation at room temperature, the plate was washed and developed with phosphatase substrate (MilliporeSigma) at room temperature. The plates were immediately read at $405 \mathrm{~nm}$, with 5 -min incubations at room temperature between reads.

\section{Statistics}

The main outcome measure in this study is the viremia levels on mAbtreated and control animals. We did not perform statistical comparisons, because there was no virus detected in any of the treated animals and all controls got infected.

\section{SUPPLEMENTARY MATERIALS}

www.sciencetranslationalmedicine.org/cgi/content/full/9/410/eaan8184/DC1

Fig. S1. Plasmablast-derived human mAbs neutralize ZIKV in vitro.

Fig. S2. Epitope mapping: SMZAb1, SMZAb2, and SMZAb5 ZIKV E protein epitope specificity was evaluated.

Fig. S3. Binding of SMZAb1, SMZAb2, and SMZAb5 to whole ZIKV or DENV was evaluated by virus capture ELISA using $4 \mathrm{G} 2$.

Fig. S4. DENV neutralization by SMZAbs.

Fig. S5. ZIKV-neutralizing activity after mAb infusion (FRNT).

Table S1. SMZAb amino acid sequences.

Table S2. Neutralization of ZIKV strains and DENV serotypes by SMZAbs (FRNT $50 \mu \mathrm{g} \mathrm{ml}^{-1}$ ).

Table S3. ZIKV Paraiba/2015 neutralization by SMZAbs before infusion.

Table S4. Study animals.

Table S5. Viral titers $\left(\log _{10}\right.$ PFU $\mathrm{ml}^{-1}$ ) in serum after ZIKV challenge.

Table S6. Viral titers (vRNA copies $\mathrm{ml}^{-1}$ ) in serum after ZIKV challenge.

\section{REFERENCES AND NOTES}

1. M. R. Reynolds, A. M. Jones, E. E. Petersen, E. H. Lee, M. E. Rice, A. Bingham, S. R. Ellington, N. Evert, S. Reagan-Steiner, T. Oduyebo, C. M. Brown, S. Martin, N. Ahmad, J. Bhatnagar, J. Macdonald, C. Gould, A. D. Fine, K. D. Polen, H. Lake-Burger, C. L. Hillard, N. Hall, M. M. Yazdy, K. Slaughter, J. N. Sommer, A. Adamski, M. Raycraft, S. Fleck-Derderian, J. Gupta, K. Newsome, M. Baez-Santiago, S. Slavinski, J. L. White, C. A. Moore, C. K. Shapiro-Mendoza, L. Petersen, C. Boyle, D. J. Jamieson, D. Meaney-Delman, M. A. Honein; U.S. Zika Pregnancy Registry Collaboration, Vital signs: Update on Zika virus-associated birth defects and evaluation of all U.S. infants with congenital Zika virus exposure-U.S. Zika Pregnancy Registry, 2016. MMWR Morb. Mortal. Wkly Rep. 66, 366-373 (2017).

2. P. Brasil, J. P. Pereira Jr., M. E. Moreira, R. M. Ribeiro Nogueira, L. Damasceno, M. Wakimoto, R. S. Rabello, S. G. Valderramos, U.-A. Halai, T. S. Salles, A. A. Zin, D. Horovitz, P. Daltro, M. Boechat, C. Raja Gabaglia, P. Carvalho de Sequeira, J. H. Pilotto, R. Medialdea-Carrera, D. Cotrim da Cunha, L. M. Abreu de Carvalho, M. Pone, A. Machado Siqueira, G. A. Calvet, A. E. Rodrigues Baião, E. S. Neves, P. R. Nassar de Carvalho, R. H. Hasue, P. B. Marschik, C. Einspieler, C. Janzen, J. D. Cherry, A. M. Bispo de Filippis, K. Nielsen-Saines, Zika virus infection in pregnant women in Rio de Janeiro. N. Engl. J. Med. 375, 2321-2334 (2016).

3. J. Mlakar, M. Korva, N. Tul, M. Popović, M. Poljšak-Prijatelj, J. Mraz, M. Kolenc, K. Resman Rus, T. Vesnaver Vipotnik, V. Fabjan Vodušek, A. Vizjak, J. Pižem, M. Petrovec, T. Avšič Županc, Zika virus associated with microcephaly. N. Engl. J. Med. 374, 951-958 (2016).
4. World Health Organization, Fifth Meeting of the Emergency Committee Under the International Health Regulations (2005) Regarding Microcephaly, Other Neurological Disorders and Zika Virus (World Health Organization, 2016); www.who.int/mediacentre/ news/statements/2016/zika-fifth-ec/en/ [accessed 24 August 2017].

5. The IMpact-RSV Study Group, Palivizumab, a humanized respiratory syncytial virus monoclonal antibody, reduces hospitalization from respiratory syncytial virus infection in high-risk infants. Pediatrics 102, 531-537 (1998).

6. J. Jückstock, M. Rothenburger, K. Friese, F. Traunmüller, Passive immunization against congenital cytomegalovirus infection: Current state of knowledge. Pharmacology 95, 209-217 (2015).

7. N. E. Simister, Placental transport of immunoglobulin G. Vaccine 21, 3365-3369 (2003).

8. G. Barba-Spaeth, W. Dejnirattisai, A. Rouvinski, M.-C. Vaney, I. Medits, A. Sharma, E. Simon-Lorière, A. Sakuntabhai, V.-M. Cao-Lormeau, A. Haouz, P. England, K. Stiasny, J. Mongkolsapaya, F. X. Heinz, G. R. Screaton, F. A. Rey, Structural basis of potent Zikadengue virus antibody cross-neutralization. Nature 536, 48-53 (2016).

9. C.-J. Lai, A. P. Goncalvez, R. Men, C. Wernly, O. Donau, R. E. Engle, R. H. Purcell, Epitope determinants of a chimpanzee dengue virus type 4 (DENV-4)-neutralizing antibody and protection against DENV-4 challenge in mice and rhesus monkeys by passively transferred humanized antibody. J. Virol. 81, 12766-12774 (2007).

10. D. M. Magnani, M. J. Ricciardi, V. K. Bailey, M. J. Gutman, N. Pedreño-Lopez, C. G. T. Silveira, H. S. Maxwell, A. Domingues, L. Gonzalez-Nieto, Q. Su, R. M. Newman, M. Pack, M. A. Martins, J. M. Martinez-Navio, S. P. Fuchs, E. G. Rakasz, T. M. Allen, S. S. Whitehead, D. R. Burton, G. Gao, R. C. Desrosiers, E. G. Kallas, D. I. Watkins, Dengue virus evades AAV-mediated neutralizing antibody prophylaxis in rhesus monkeys. Mol. Ther. (2017).

11. S. Sukupolvi-Petty, S. K. Austin, M. Engle, J. D. Brien, K. A. Dowd, K. L. Williams, S. Johnson, R. Rico-Hesse, E. Harris, T. C. Pierson, D. H. Fremont, M. S. Diamond, Structure and function analysis of therapeutic monoclonal antibodies against dengue virus type 2. J. Virol. 84, 9227-9239 (2010).

12. A. J. Hessell, L. Hangartner, M. Hunter, C. E. G. Havenith, F. J. Beurskens, J. M. Bakker, C. M. S. Lanigan, G. Landucci, D. N. Forthal, P. W. H. I. Parren, P. A. Marx, D. R. Burton, Fc receptor but not complement binding is important in antibody protection against HIV. Nature 449, 101-104 (2007).

13. M. C. Bonaldo, I. P. Ribeiro, N. S. Lima, A. A. C. Dos Santos, L. S. R. Menezes, S. O. D. da Cruz, I. S. de Mello, N. D. Furtado, E. E. de Moura, L. Damasceno, K. A. B. da Silva, M. G. de Castro, A. L. Gerber, L. G. P. de Almeida, R. Lourenço-de-Oliveira, A. T. R. Vasconcelos, P. Brasil, Isolation of infective Zika virus from urine and saliva of patients in Brazil. PLOS Negl. Trop. Dis. 10, e0004816 (2016).

14. L. M. Styer, K. A. Kent, R. G. Albright, C. J. Bennett, L. D. Kramer, K. A. Bernard, Mosquitoes inoculate high doses of West Nile virus as they probe and feed on live hosts. PLOS Pathog. 3, 1262-1270 (2007).

15. R. A. Larocca, P. Abbink, J. P. S. Peron, P. M. A. Zanotto, M. J. lampietro, A. Badamchi-Zadeh, M. Boyd, D. Ng'ang'a, M. Kirilova, R. Nityanandam, N. B. Mercado, Z. Li, E. T. Moseley, C. A. Bricault, E. N. Borducchi, P. B. Giglio, D. Jetton, G. Neubauer, J. P. Nkolola, L. F. Maxfield R. A. De La Barrera, R. G. Jarman, K. H. Eckels, N. L. Michael, S. J. Thomas, D. H. Barouch, Vaccine protection against Zika virus from Brazil. Nature 536, 474-478 (2016).

16. K. A. Dowd, S.-Y. Ko, K. M. Morabito, E. S. Yang, R. S. Pelc, C. R. DeMaso, L. R. Castilho, P. Abbink, M. Boyd, R. Nityanandam, D. N. Gordon, J. R. Gallagher, X. Chen, J.-P. Todd, Y. Tsybovsky, A. Harris, Y.-J. S. Huang, S. Higgs, D. L. Vanlandingham, H. Andersen, M. G. Lewis, R. De La Barrera, K. H. Eckels, R. G. Jarman, M. C. Nason, D. H. Barouch, M. Roederer, W.-P. Kong, J. R. Mascola, T. C. Pierson, B. S. Graham, Rapid development of a DNA vaccine for Zika virus. Science 354, 237-240 (2016).

17. H. D. Marston, N. Lurie, L. L. Borio, A. S. Fauci, Considerations for developing a Zika virus vaccine. N. Engl. J. Med. 375, 1209-1212 (2016).

18. T. T. Wang, J. Sewatanon, M. J. Memoli, J. Wrammert, S. Bournazos, S. K. Bhaumik, B. A. Pinsky, K. Chokephaibulkit, N. Onlamoon, K. Pattanapanyasat, J. K. Taubenberger, R. Ahmed, J. V. Ravetch, IgG antibodies to dengue enhanced for Fc $\gamma$ RIIIA binding determine disease severity. Science 355, 395-398 (2017).

19. S. B. Halstead, In vivo enhancement of dengue virus infection in rhesus monkeys by passively transferred antibody. J. Infect. Dis. 140, 527-533 (1979).

20. K. A. Dowd, T. C. Pierson, Antibody-mediated neutralization of flaviviruses: A reductionist view. Virology 411, 306-315 (2011).

21. M. G. Guzman, M. Alvarez, S. B. Halstead, Secondary infection as a risk factor for dengue hemorrhagic fever/dengue shock syndrome: An historical perspective and role of antibody-dependent enhancement of infection. Arch. Virol. 158, 1445-1459 (2013).

22. S. V. Bardina, P. Bunduc, S. Tripathi, J. Duehr, J. J. Frere, J. A. Brown, R. Nachbagauer, G. A. Foster, D. Krysztof, D. Tortorella, S. L. Stramer, A. García-Sastre, F. Krammer, J. K. Lim, Enhancement of Zika virus pathogenesis by preexisting antiflavivirus immunity. Science 356, 175-180 (2017).

23. W. Dejnirattisai, P. Supasa, W. Wongwiwat, A. Rouvinski, G. Barba-Spaeth, T. Duangchinda, A.Sakuntabhai, V.-M. Cao-Lormeau, P. Malasit, F. A. Rey, J. Mongkolsapaya, G. R. Screaton, Dengue virus sero-cross-reactivity drives antibody-dependent enhancement of infection with Zika virus. Nat. Immunol. 17, 1102-1108 (2016). 
24. L. Priyamvada, K. M. Quicke, W. H. Hudson, N. Onlamoon, J. Sewatanon, S. Edupuganti, K. Pattanapanyasat, K. Chokephaibulkit, M. J. Mulligan, P. C. Wilson, R. Ahmed, M. S. Suthar, J. Wrammert, Human antibody responses after dengue virus infection are highly cross-reactive to Zika virus. Proc. Natl. Acad. Sci. U.S.A. 113, 7852-7857 (2016).

25. G. J. Robbie, R. Criste, W. F. Dall'acqua, K. Jensen, N. K. Patel, G. A. Losonsky, M. P. Griffin, A novel investigational Fc-modified humanized monoclonal antibody, motavizumab-YTE, has an extended half-life in healthy adults. Antimicrob. Agents Chemother. 57, 6147-6153 (2013).

26. G. Sapparapu, E. Fernandez, N. Kose, B. Cao, J. M. Fox, R. G. Bombardi, H. Zhao, C. A. Nelson, A. L. Bryan, T. Barnes, E. Davidson, I. U. Mysorekar, D. H. Fremont, B. J. Doranz, M. S. Diamond, J. E. Crowe, Neutralizing human antibodies prevent Zika virus replication and fetal disease in mice. Nature 540, 443-447 (2016).

27. A. P. Durbin, R. A. Karron, W. Sun, D. W. Vaughn, M. J. Reynolds, J. R. Perreault, B. Thumar, R. Men, C.-J. Lai, W. R. Elkins, R. M. Chanock, B. R. Murphy, S. S. Whitehead, Attenuation and immunogenicity in humans of a live dengue virus type-4 vaccine candidate with a 30 nucleotide deletion in its 3'-untranslated region. Am. J. Trop. Med. Hyg. 65, 405-413 (2001)

28. I. J. Fuss, M. E. Kanof, P. D. Smith, H. Zola, Isolation of whole mononuclear cells from peripheral blood and cord blood. Curr. Protoc. Immunol. Chapter 7, Unit7.1 (2009).

29. J. D. Brien, H. M. Lazear, M. S. Diamond, Propagation, quantification, detection, and storage of West Nile virus. Curr. Protoc. Microbiol. 31, 15D.3.1-15D.3.18 (2013).

30. R. de Alwis, A. M. de Silva, Measuring antibody neutralization of dengue virus (DENV) using a flow cytometry-based technique. Methods Mol. Biol. 1138, 27-39 (2014).

31. A. A. Kraus, W. Messer, L. B. Haymore, A. M. de Silva, Comparison of plaque- and flow cytometry-based methods for measuring dengue virus neutralization. J. Clin. Microbiol. 45, 3777-3780 (2007)

32. G. A. Santiago, E. Vergne, Y. Quiles, J. Cosme, J. Vazquez, J. F. Medina, F. Medina, C. Colón, H. Margolis, J. L. Muñoz-Jordán, Analytical and clinical performance of the CDC real time RT-PCR assay for detection and typing of dengue virus. PLOS Negl. Trop. Dis. 7, e2311 (2013).

33. B. W. Johnson, B. J. Russell, R. S. Lanciotti, Serotype-specific detection of dengue viruses in a fourplex real-time reverse transcriptase PCR assay. J. Clin. Microbiol. 43, 4977-4983 (2005).

34. H. Zhao, E. Fernandez, K. A. Dowd, S. D. Speer, D. J. Platt, M. J. Gorman, J. Govero, C. A. Nelson, T. C. Pierson, M. S. Diamond, D. H. Fremont, Structural basis of Zika virusspecific antibody protection. Cell 166, 1016-1027 (2016).

35. T. F. Rogers, E. C. Goodwin, B. Briney, D. Sok, N. Beutler, A. Strubel, R. Nedellec, K. Le, M. E. Brown, D. R. Burton, L. M. Walker, Zika virus activates de novo and cross-reactive memory B cell responses in dengue-experienced donors. Sci. Immunol. 2, eaan6809 (2017).
Acknowledgments: We thank the veterinary and animal care staff for providing care of the rhesus macaques included in this experiment. Funding: This work was supported by $\mathrm{NIH}$ grant 4P01Al094420-05, the Wallace H. Coulter Center for Translational Research at the University of Miami, the Miami Clinical and Translational Science Institute (CTSI), and the Intramural Research Program of the National Institute of Allergy and Infectious Diseases, NIH. This research was also supported in part by the Defense Advanced Research Projects Agency (DARPA) Autonomous Diagnostics to Enable Prevention and Therapeutics: Prophylactic Options to Environmental and Contagious Threats (ADEPT-PROTECT) program (W31P4Q-13-1-0011), as well as NIH grant P30AI073961 to the Miami Center for AIDS Research and grant P51 OD011132 to the YNPRC. The content is solely the responsibility of the authors and does not necessarily represent the official views of the NIH. The funders had no role in study design, data collection, and analysis, decision to publish, or preparation of the manuscript. Author contributions: D.M.M., T.F.R., G.S., E.G.K., R.C.D., T.H.V., S.S.W., D.R.B., and D.I.W. planned the studies. D.M.M., T.F.R., N.B., A.S., M.J.R., B.B., D.S., K.L., N.D.G., V.K.B., L.G.-N., N.P.-L., M.J.G., C.G.T.S., H.S.M., A.D., M.A.M., D.E.L., E.E.O., S.J., E.A.S., A.C., T.H.V., and S.S.W. conducted the experiments. M.C.B. provided reagents. D.M.M., T.F.R., G.S., E.G.K., R.C.D., S.W., D.R.B., and D.I.W. interpreted the studies. D.M.M., T.F.R., D.R.B., and D.I.W. wrote the first draft. T.F.R., G.S., S.S.W., D.R.B., and D.I.W. obtained funding. All authors reviewed, edited, and approved the paper. Competing interests: D.R.B. and T.F.R. are inventors on a patent application submitted by The Scripps Research Institute that covers anti-Zika monoclonal antibodies. All other authors declare that they have no competing interests. Data and materials availability: The antibody sequences are provided in the Supplementary Materials.

Submitted 23 May 2017

Accepted 24 August 2017

Published 4 October 2017

10.1126/scitransImed.aan8184

Citation: D. M. Magnani, T. F. Rogers, N. Beutler, M. J. Ricciardi, V. K. Bailey, L. Gonzalez-Nieto, B. Briney, D. Sok, K. Le, A. Strubel, M. J. Gutman, N. Pedreño-Lopez, N. D. Grubaugh, C. G. T. Silveira, H. S. Maxwell, A. Domingues, M. A. Martins, D. E. Lee, E. E. Okwuazi, S. Jean, E. A. Strobert, A. Chahroudi, G. Silvestri, T. H. Vanderford, E. G. Kallas, R. C. Desrosiers, M. C. Bonaldo, S. S. Whitehead, D. R. Burton, D. I. Watkins, Neutralizing human monoclonal antibodies prevent Zika virus infection in macaques. Sci. Transl. Med. 9, eaan8184 (2017). 


\section{Science Translational Medicine}

\section{Neutralizing human monoclonal antibodies prevent Zika virus infection in macaques}

Diogo M. Magnani, Thomas F. Rogers, Nathan Beutler, Michael J. Ricciardi, Varian K. Bailey, Lucas Gonzalez-Nieto, Bryan Briney, Devin Sok, Khoa Le, Alexander Strubel, Martin J. Gutman, Núria Pedreño-Lopez, Nathan D. Grubaugh, Cassia G. T. Silveira, Helen S. Maxwell, Aline Domingues, Mauricio A. Martins, David E. Lee, Erica E. Okwuazi, Sherrie Jean, Elizabeth A. Strobert, Ann Chahroudi, Guido Silvestri, Thomas H. Vanderford, Esper G. Kallas, Ronald C. Desrosiers, Myrna C. Bonaldo, Stephen S. Whitehead, Dennis R. Burton and David I. Watkins

Sci Transl Med 9, eaan8184.

DOI: $10.1126 /$ scitransImed.aan8184

\section{Antibodies provide promising Zika prophylaxis}

The recent Zika virus epidemic and ensuing fetal consequences caught the world off guard. Scientists are now scrambling for information on Zika virus detection, treatment, and prevention. Passive immunity provided by monoclonal antibodies offers an attractive alternative to traditional vaccines, because it can be generated relatively quickly. Magnani et al. isolated and engineered three neutralizing antibodies from a Zika-infected patient. Administration of these antibodies completely protected nonhuman primates from becoming infected with Zika virus, suggesting that such a cocktail could be used to prevent Zika infections in people.

ARTICLE TOOLS

SUPPLEMENTARY

MATERIALS

RELATED

CONTENT

REFERENCES

PERMISSIONS http://stm.sciencemag.org/content/9/410/eaan8184

http://stm.sciencemag.org/content/suppl/2017/10/02/9.410.eaan8184.DC1 http://stm.sciencemag.org/content/scitransmed/8/330/330ed2.full http://stm.sciencemag.org/content/scitransmed/9/384/eaai8711.full http://stm.sciencemag.org/content/scitransmed/9/388/eaag0538.full http://stm.sciencemag.org/content/scitransmed/9/409/eaan1589.full

This article cites 33 articles, 12 of which you can access for free http://stm.sciencemag.org/content/9/410/eaan8184\#BIBL

http://www.sciencemag.org/help/reprints-and-permissions

Use of this article is subject to the Terms of Service

Science Translational Medicine (ISSN 1946-6242) is published by the American Association for the Advancement of Science, 1200 New York Avenue NW, Washington, DC 20005. 2017 (C) The Authors, some rights reserved; exclusive licensee American Association for the Advancement of Science. No claim to original U.S. Government Works. The title Science Translational Medicine is a registered trademark of AAAS. 